\title{
The completion of visual forms across hemianopic field defects
}

\author{
ELIZABETH K. WARRINGTON \\ From the National Hospital, Queen's Square, London
}

The fact that visual forms were 'completed' across blind sections of the visual field in patients with hemianopia was discovered by Poppelreuter (1917) when working with brief exposures of geometrical figures presented tachistoscopically. When a figure was exposed on the tachistoscope screen so that it overlapped the blind part of the visual field, the patients still reported seeing the whole figure, though it was objectively impossible for them to have done so (Fig. 1). Poppelreuter found this to be the case with filled-in figures and to a lesser extent with outline figures. He could produce the same result equally well by presenting an objectively incomplete form so that the missing part fell in the blind field of vision. Poppelreuter pointed out that 'the paradox is that the patient apparently sees with his blind field'. He called the phenomenon the 'Vorstellungsmässige Ergänzung' (imaginative completion) of familiar shapes, analogous to filling-in of the blind spot or of areas beyond the periphery of the normal visual field (Helmholtz, 1924-5). He interpreted it as a means of compensating for the hemianopia, and suggested that it might also result in patients failing to become aware of their visual field defects. However, he also reported that two of his patients with right homonymous hemianopia did not complete, and his interpretation cannot account for these exceptions. If 'completion' reflects normal perceptual processes all patients with field defects would be expected to show it.

Further work has failed materially to increase knowledge of this phenomenon. Fuchs (1920) confirmed the observations of Poppelreuter and put forward an explanation in terms of the Gestalt theory of perception (Koffka, 1935). He regarded the completion effect as central in origin and as the outcome of 'field forces' tending to produce a symmetrical and well-balanced configuration. In support of this view Fuchs stressed that genuinely incomplete figures are completed (thus excluding residual vision in the affected field) and claimed that the effect is found only with simple, regular, and symmetrical forms. Again this does not explain the absence of completion in many of his hemianopic patients.

Bender and Teuber (1946) studied three patients with field defects and claimed, in contrast to

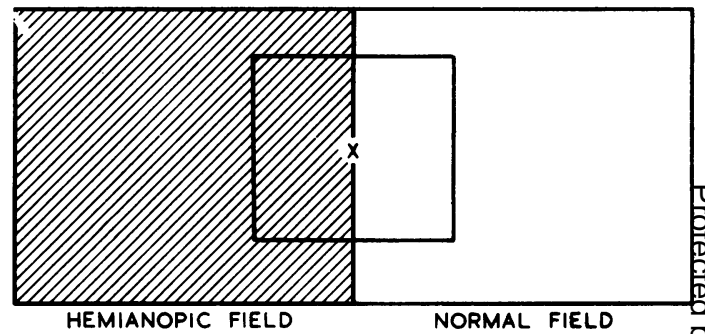

\section{PRESENTED}

OBJECTIVELY VISIBLE

REPORTED BY 'COMPLETER'

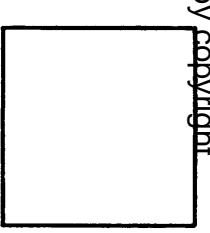

REPORTED BY 'NON-COMPLETER'

FIG. 1. Diagrams of tachistoscopic field. 
Poppelreuter and Fuchs, that only objectively intact forms are completed. (The evidence is limited because only one patient was tested with only one incomplete figure.) Therefore, they suggested, completion may be indicative of some residual vision in the 'blind' parts of the field, detectable only under special conditions.

The possibility of residual vision in the defective field causing apparent completion was further pursued by Pollack, Battersby, and Bender (1957) in a study of 23 cases with homonymous hemianopia, 10 of which showed the completion phenomenon. They found that incomplete figures were as effective as complete, thus refuting Bender and Teuber's thesis. Further, they reported a statistically significant relationship between completion and 'mental confusion'. They did not state their criteria for 'mental confusion'.

The present work was undertaken to place the phenomenon of completion on a quantitative basis, and to find out in what ways patients who show completion differ from those who do not.

\section{THE EXPERIMENTAL STUDY}

SUBJECTS Sixty subjects took part in this experiment. These were divided into three groups.

Group I Twenty patients with complete homonymous hemianopia were selected solely because they had a visual field defect, irrespective of whether or not there was a well-localized cerebral lesion.

Group II Twenty patients with a variety of cerebral cortical lesions comprising 15 patients with well-localised lesions and five with diffuse cerebral cortical damage.

Group III Twenty healthy subjects comparable with the groups of patients from the point of view of age, sex, and occupation.
A brief clinical history of each of the hemianopic patients is given in appendix I and each includes the classification according to the site of the lesion adopted in this study.

VISUAL FIELD AND VISUAL ACUITY Field defects were ascertained on tests of confrontation. Acuity was measured in all but three of the patients in group I by means of the Snellen chart and Jaeger types (Table I). These tests formed part of the routine neurological examination but information as to macular sparing was not available in many of these patients.

SUBJECTIVE FIELD OF VISION Subjective awareness of the hemianopic field defect is very variable and ranges from total denial of any disability to a very accurate account of the shape and extent of the blind area (Critchley, 1950). All patients with a homonymous hemianopia were questioned about their subjective field of vision. For the purposes of this study these patients were considered to have adequate or inadequate awareness of their visual field defect, depending on their answer to the question. 'Can you see equally well to your left and right?' Only those patients who answered in the affirmative were classified as not being adequately aware of their visual field defect. Using this criterion of awareness of the visual field defect, all patients with partial awareness of the visual field defect are included with those cases in which insight into the field defect was good (Table I). Eleven of the hemianopic patients did not have adequate awareness of the visual defect.

UNILATERAL SPATIAL NEGLECT Failure to appreciate one half of extrapersonal space is not uncommonly observed in patients with cerebral lesions involving the posterior parietal areas. It may result in failure to notice doors or turnings on one or other side, to the neglect of one side of a picture, and to omission of faulty reproduction of one side of a drawing (Critchley, 1953). All patients in

TABLE I

CLINICAL DATA FOR PRESENT SERIES

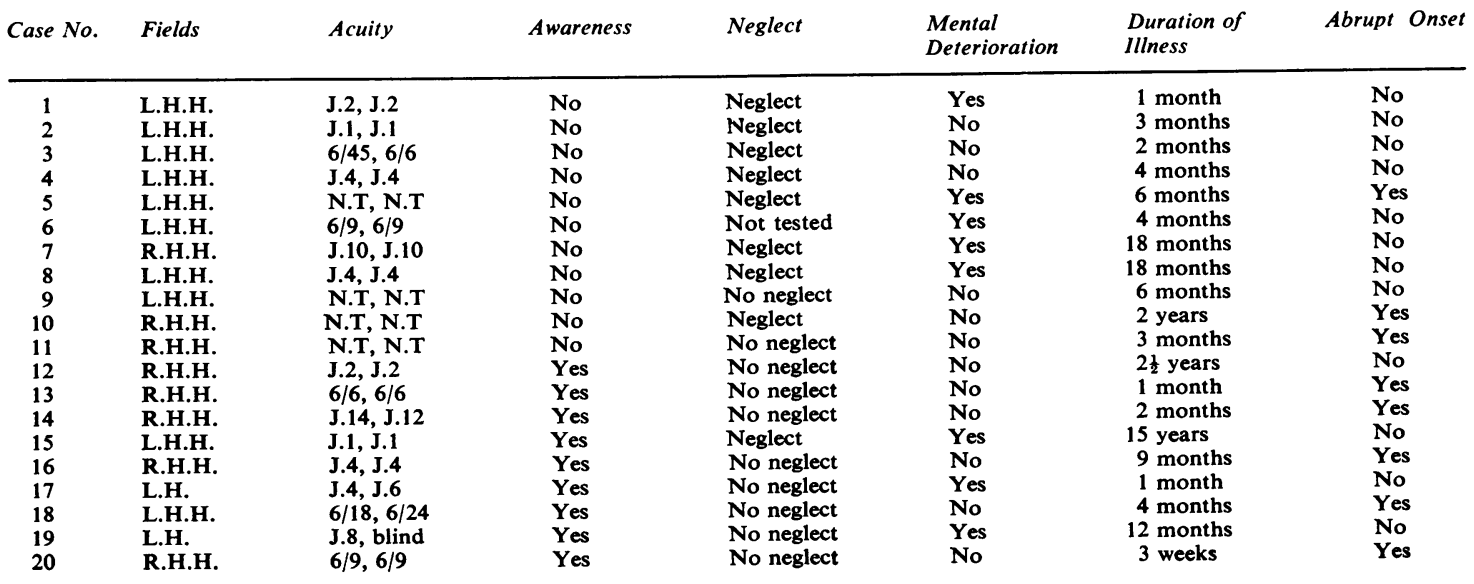


this series were examined for unilateral neglect; the symptom was present in varying degree in eight of the patients; in six the side neglected was the left (Table I).

MENTAL DETERIORATION Not all the patients in this series were fully assessed psychologically but they were all fully cooperative and able to carry out instructions and maintain concentration for the duration of the experiment. The clinician's assessment of the presence or absence of mental deterioration was accepted for the purposes of this study. Any patient showing frank signs of dementia or mental deterioration was classified as 'mentally deteriorated' (Table I). In this series there were eight patients with evidence of mental deterioration.

DURATION OF ILLNESS The duration of illness was established as the time elapsing between the date on which a neurological symptom was first reported and the date of psychological tests. It was also noted whether the onset of the illness was abrupt or insidious (Table I).

\section{METHOD}

A tachistoscope of Dodge type (Dodge, 1907) was used. The background and exposure field were both $6 \times 4$ in., subtending a horizontal angle of $14^{\circ}$ at the retina $\left(7^{\circ}\right.$ either side of the fixation point), and were matched for brightness and colour. Exposure time of the stimulus field ranged from $2 \mathrm{msec}$. to $1,600 \mathrm{msec}$. according to a logarithmic scale. The resultant series is $2 \cdot 0,2 \cdot 5,3 \cdot 2$, $4 \cdot 0,5 \cdot 0,6 \cdot 4,8 \cdot 0,10 \cdot 0,12 \cdot 5$, and $16 \cdot 0 \mathrm{msec}$. Multiplying factors of 10 and 100 were used to extend the range. Further details of the apparatus are given by Kinsbourne and Warrington (1962).

The figures used were drawn in black ink on white cards $6 \times 4$ in. They comprised a circle, square, oblong, star, and cross. Each form was drawn as a whole and as a half figure, making 10 stimulus cards in all (Fig. 2). Each half figure subtended $2^{\circ}$ at the retina.

The following general instructions were given:-

'I want you to look at the small cross in the centre of the screen. When I say "ready" a drawing will appear on the screen for a very short time. I want you to tell me exactly what you saw. It is important to tell me what you actually saw, not what you think may have been there. I do not want you to guess. Between each exposure you may move your eyes about, but when I say "ready" you must look at the small cross.'

Whenever a subject or patient responded by giving a 'complete' response, that is, reported seeing a whole figure, he was asked specifically, 'Did you see all of it?'

The 10 figures used in this experiment (see Fig. 2) were arranged in three different orders such that there were never more than two whole shapes or the whole and the half form of the same shape in sequence. That is, the whole circle would never be followed by the half circle, and though the whole square might be followed by the whole oblong, the next card in sequence would be a half figure.

Every subject was shown each figure three times, using each of the three orders in random sequence. Each figure was presented in an ascending series of exposure times, until the 'recognition threshold' was attained. This was taken to be accurate recognition of the figure or accurate recognition of that part of the figure falling in the patient's intact field of vision.

Thus if a patient with a hemianopic field defect were shown a circle and reported it as a whole circle, this would be accepted as fulfilling the requirement of
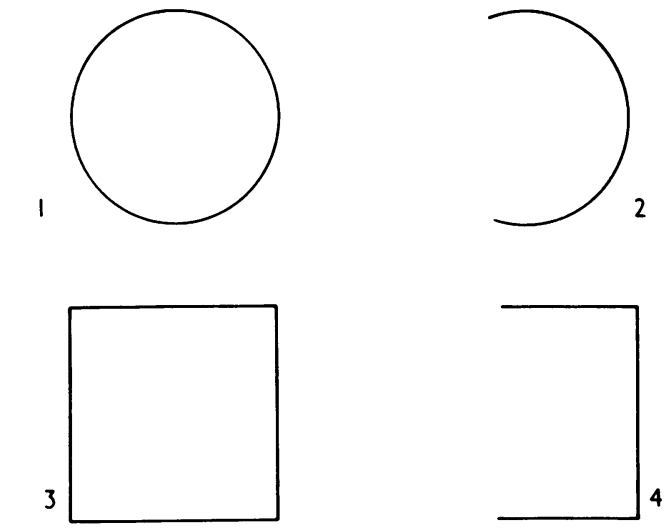

7
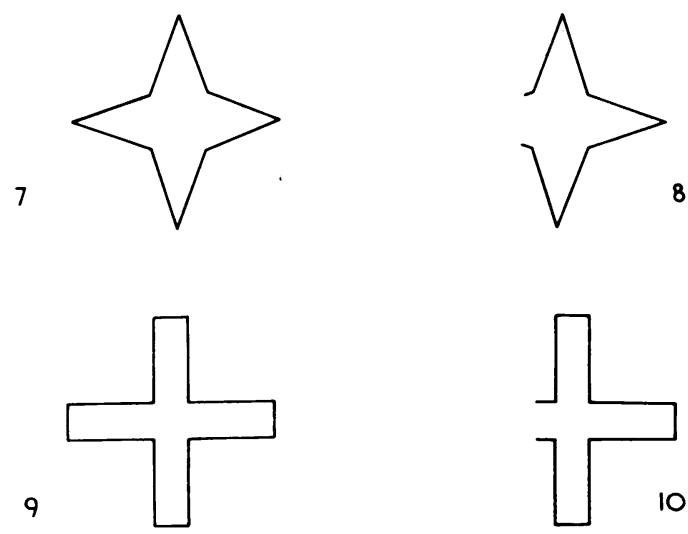

Figures $1-10$

EXPERIMENT 1.

FIG. 2. Whole and half figures used for testing. 
accurate recognition of the part of the figure falling in the intact field of vision. The same figure was then presented at exposure times above threshold. First, the threshold time was increased by a minimum value, i.e., 1 unit, and then by a multiplying factor of 10 ; finally the maximum exposure time was used $(1,600 \mathrm{msec}$.). Exposure at 1 unit above threshold does not permit of reactive eye movements (Diefendorf and Dodge, 1908). The other two conditions of exposure time cannot be assumed to exclude eye movements.

To the control patients with cerebral lesions unassociated with a visual field defect half figures were presented in the half field contralateral to the lesion. Of the normal subjects, 10 were tested with half figures in the right half field and 10 with half figures in the left half field.

\section{FINDINGS}

THRESHOLDS The recognition threshold was taken to be the minimum duration of exposure necessary for accurate recognition of that part of the test figure falling within the intact area of the visual field. These values (in msec.) were then assigned to a position on an arithmetical scale varying from 1 to 30 , such that each number represents one of the 30 possible exposure times. (The shortest exposure time, 2 msec., was placed in position 1 , and the longest exposure time, $1,600 \mathrm{~m} \mathrm{sec}$, in position 30.$)$ Any patient who failed to achieve the criterion of threshold recognition at this maximum exposure time was given a value of 30 .

The mean recognition threshold for groups I, II, and III was $18 \cdot 3,16 \cdot 7$, and $10 \cdot 2$ respectively. Statistical analysis of this result showed that the mean recognition thresholds for the normal control subjects were significantly lower than those for either the hemianopic or the non-hemianopic patients but that there was no significant difference between the hemianopic and non-hemianopic groups.

COMPLETION AT THRESHOLD AND ABOVE THRESHOLD The percentage distribution of completion of half figures at threshold is shown for the hemianopic and non-hemianopic patient groups and the control group separately in Fig. 3a. For the hemianopic group the completion responses for the whole and the half figures are shown separately and combined in Fig. 3b.

The percentage distribution of complete responses for the half figures in the hemianopic group was bimodal. Eleven of the 20 patients showed $60 \%$ or more completion and nine showed $30 \%$ or less

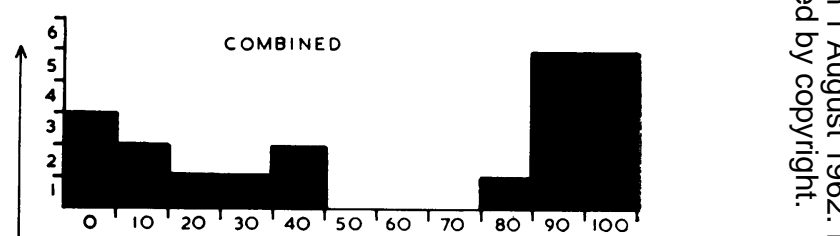

FIG. $3 \mathrm{a}$
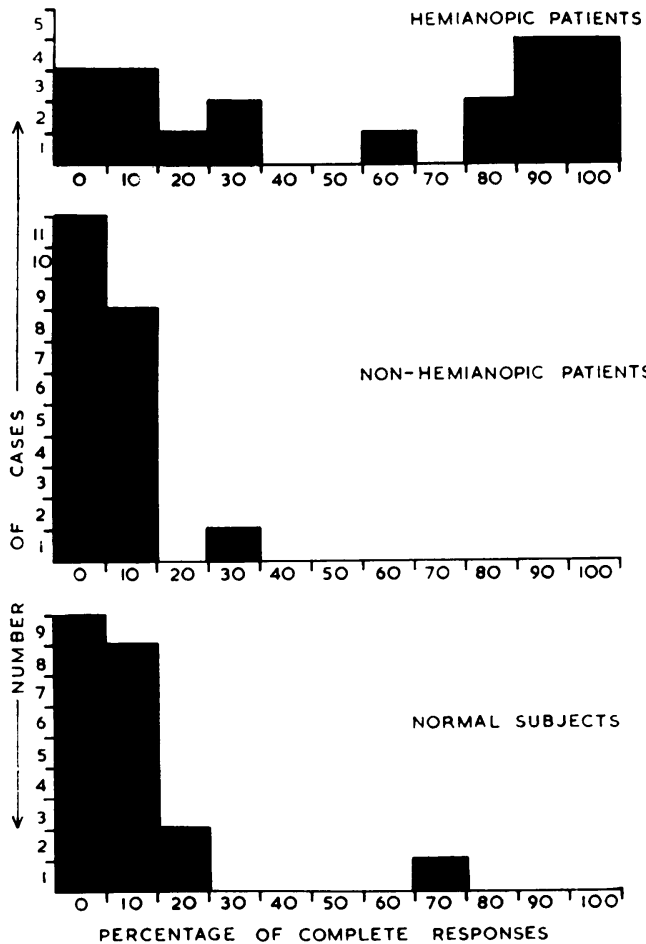

uั

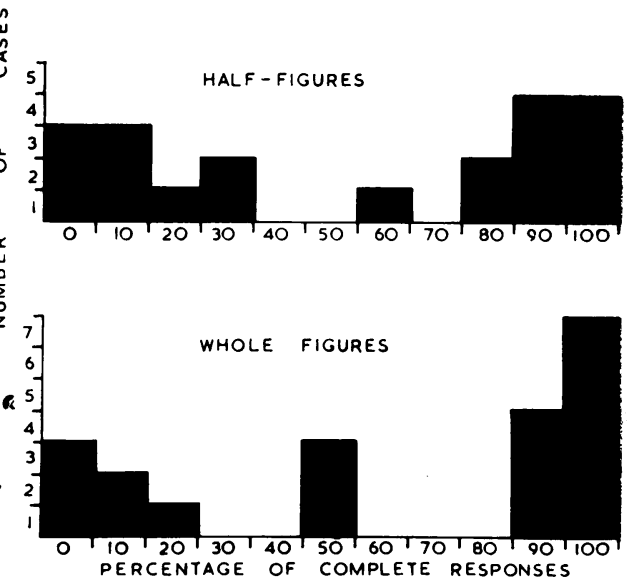

FIG. 3 b

FIG. 3. Percentage distribution of complete responses to (a) half figures by hemianopic patients, non-hemianopic patients, and normal subjects; (b) whole and half figures by hemianopic patients. 
TABLE II

RANGE OF COMPLETE RESPONSES

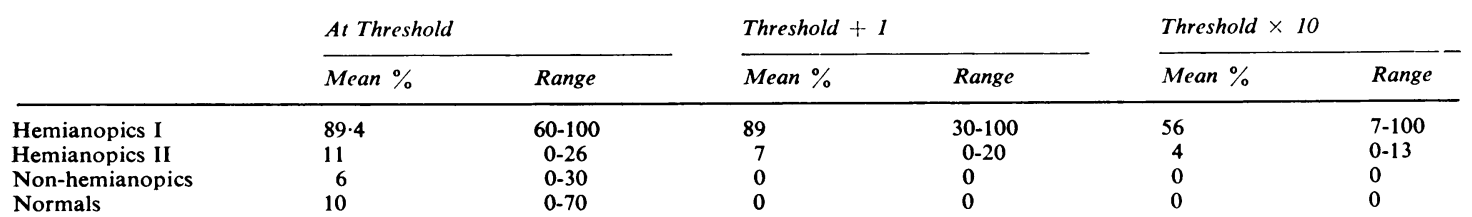

completion (median, $10 \%$ ). For the whole figures the distribution of complete responses was more scattered over the whole range from 0 to $100 \%$. Nevertheless, those individuals who showed $60 \%$ or more completion for the half figures now came within the range 90 to $100 \%$ of complete responses. But individuals who showed only 0 to $30 \%$ completion for the half figures now came within the range of 0 to $50 \%$. If the results for the whole and the half figure were combined there was again a bimodal distribution of cases along the continuum of percentage of complete responses; 13 subjects showed $80 \%$ or more complete responses and the other 13 showed $40 \%$ or less.

For the purpose of further analysis the hemianopic cases were subdivided into two groups. These were the 'completion group' (patients showing $80 \%$ or more complete responses, group Ia) and the 'nocompletion group' (patients showing $40 \%$ or less complete responses, group Ib).

The distribution of complete responses in the non-hemianopic patients and the control subjects (see Fig. 3) was comparable to that of the hemianopic patients who showed 'no completion'. The mean percentage of completion for these two groups was 0 and 10 respectively and for the 'no completion' cases it was 10. The mean percentage and range of complete responses to half figures by the three groups of subjects are shown in Table II.

The distribution of complete responses by the hemianopic patients at exposure times greater than the threshold value is shown in Fig. 4. With a minimal increase in exposure time there was no decrease in the number of complete responses. When the exposure time was increased by a multiplying factor of 10 above the threshold the distribution of complete responses by the hemianopic patients was more scattered over the range of 0 to $100 \%$. Nevertheless four cases still showed completion using the criterion of more than $80 \%$ complete responses. The mean percentage and range of percentages of complete responses are given in Table II. In neither control group were any complete responses given at exposure times other than at threshold.

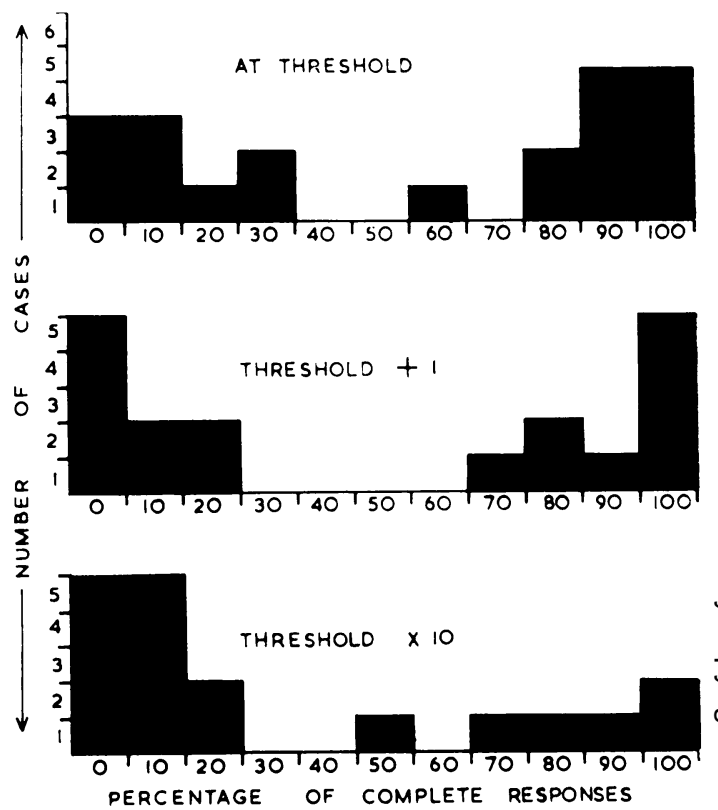

FIG. 4. Percentage distribution of complete responses at increasing exposure times by hemianopic patients.

COMPARISON OF GROUPS Ia AND Ib It has been shown in the previous section that patients with hemianopia may be divided into two groups according to whether the completion effect was present or absent. These groups, categorized solely on the basis of completion, may now be compared with a view to establishing other common attributes.

Site of lesion The distribution of the site of the lesion in the hemianopic patients together with the number exhibiting completion in each group is set out in Table III. The results show a close association ( $\chi^{2}$ significant at the 0.01 level of probability) between the presence of a lesion involving the parietal area and completion. Eleven of the 13 patients with lesions involving the parietal lobes showed completion; no patient with a lesion not involving the parietal lobes did so. None of the five patients with 
TABLE III

RANGE OF COMPLETE RESPONSES TO HALF FIGURES

\begin{tabular}{lcc} 
Site of Lesion & $\begin{array}{c}\text { Total No. } \\
\text { of Cases }\end{array}$ & $\begin{array}{c}\text { No. of Cases Com- } \\
\text { pleting (Group I) }\end{array}$ \\
\hline Frontal & 1 & 0 \\
Temporal & 1 & 0 \\
Parietal & 3 & 3 \\
Occipital & 5 & 0 \\
Fronto-parietal & 1 & 1 \\
Temporo-parietal & 2 & 1 \\
Parieto-occipital & 3 & 3 \\
Generalized (including parietal) & 4 & 3 \\
Total & 20 & 11
\end{tabular}

lesions restricted to the occipital lobes showed completion.

Awareness of field defect Eleven of the 20 patients appeared to lack insight into their field defects (Table I) and all these patients exhibited completion. No patient with adequate awareness of the field defect showed completion. This finding indicates that there is a strong association between completion and defective awareness of a field defect. In view of the fact that completion has already been shown to occur with parietal lesions, it follows that in this group of patients poor awareness of the visual disability must also be related to parietal lobe disease. All five patients with lesions limited to the occipital lobes were properly aware of their defects. In the four cases of occipitoparietal lesion, on the other hand, awareness of the field defect was very poor.

Unilateral neglect Eight patients showed evidence of unilateral neglect of extrapersonal space. Seven of these showed completion. In one patient there was evidence of unilateral neglect but no completion. The $\chi^{2}$ test showed that this demonstrates a trend for completion to be associated with unilateral neglect, but the relationship does not reach significance at the 0.05 level of probability.

Laterality of field defect A $\chi^{2}$ test of significance was used to assess the association of completion and laterality of field defect ${ }^{1}$. In this series there were 12 cases with left homonymous hemianopia and eight cases with right homonymous hemianopia (see Table I). Eight of the former and three of the latter showed completion. The $\chi^{2}$ test was not significant at the 0.05 level of probability. Therefore no association was demonstrated between completion and laterality of the field defect.

Threshold for form perception The cases in this group may be classified as having either a low threshold (12 cases) or a high threshold ${ }^{2}$ (eight

'Cases 1 and 18 were fully left-handed. Both these patients had rightsided lesions.

${ }^{2}$ Patients are classified as having a high threshold if the threshold value is greater than the mean for the whole group and as having a low threshold if it is less than the mean threshold for the group. cases). Seven of the former and four of the latter showed completion. As tested by $\chi^{2}$, this does not represent a significant relationship between completion and the threshold value at the 0.05 level of probability.

Mental deterioration In this series only eight of the patients were considered to be mentally deteriorated (see Table I) and five of these showed completion. Of the remaining 12 patients, six showed completion. A $\chi^{2}$ test of significance was used to test the association of completion and mental deterioration and showed no significant relation between the two at the 0.05 level of probability.

Length of illness The average length of illness for hemianopic patients was six months. The patients were divided into two groups, depending on whether the illness was of more (nine cases) or less (11 cases) than average duration. Six of the former and five of the latter showed completion. The $\chi^{2}$ test was used to test the significance of the association between completion and length of illness. The association was not significant at the 0.05 level of probability. Therefore no association has been shown between the incidence of completion and length of illness.

Rate of onset of illness The onset of illness was abrupt in eight of the hemianopic patients and three of these showed completion. This was not a significant correlation at the 0.05 level of probability according to the $\chi^{2}$ test.

SUMMARY OF FINDINGS The analysis indicates that the completion effect studied in these experiments is not a function of visual field defect as such. The effect is present only in the cases in which there is evidence of involvement of the parietal lobes and appears closely related to unawareness of the field defect. Further study may also show it to be related to unilateral visual neglect. Mental deterioration does not appear to be an indispensable condition for its occurrence. Further, the effect may be observed with incomplete as well as with complete forms, and with longer as well as short exposures. It appears to be unrelated to the threshold for perception of form and to the laterality of the cerebral lesions (or side of the visual field defect). In view of these considerations, any interpretation of completion must take its departure from parietal lobe symptomatology.

\section{DISCUSSION}

In a group of 20 patients with hemianopia 11 have been found to show marked completion, but in the remainder no more completion was observed than in either the normal or the control group of patients. The bimodal distribution of completion responses 
by hemianopic patients establishes that there is a clear-cut distinction between those who complete visual forms and those who do not.

The finding that not all hemianopic patients show completion is not new. It was reported by all previous workers from Poppelreuter (1917) to Pollack et al. (1957). Only the latter, however, indicated relative frequency of completion, which amounted to $40 \%$ of the cases studied and is comparable to that found in the present study $(55 \%)$. The fact that not all hemianopic patients show completion has important theoretical implications. 'Totalizing apperception,' invoked by Poppelreuter, is a process supposedly shown by normal people in relation to the blind spot and to the peripheral limits of the visual field. Poppelreuter suggested that this normal mechanism of completion is used by hemianopics to compensate for the visual field defect. But as only some patients with homonymous hemianopia complete this explanation can at best be a partial one. Although Poppelreuter mentioned that completion was absent in two of his cases he offered no explanation of this discrepancy.

The Gestalt explanation of completion (Fuchs, 1920), which has been widely accepted and indeed used as a prop for Gestalt theory (Koffka, 1935), is inadequate for the same reason. (In support of the Gestalt point of view Fuchs reported that only simple geometrical forms and not complex meaningful figures are completed. Data from the present series of patients are available (Warrington, 1960) which show conclusively that there is as great a tendency to complete complex meaningful drawings as simple geometrical forms.) A normal mechanism should not act selectively but would be expected to appear in every case unless a specific reason for its absence could be demonstrated but no such specific reason has been shown. If the tendency towards completion is regarded as a normal mechanism, it might be argued that the failure to complete found with occipital lesions was due to fixation habitually to one side of the fixation point, revealing the edge of the incomplete figures. This cannot however account for whole figures being reported as incomplete by these patients.

To account for completion as a function of residual vision in the affected half field requires that it be shown by some other test that these patients have residual vision. This was not done by Bender and Teuber (1946) nor was it attempted here as the use of half figures, which were nevertheless completed, made it unnecessary.

Another divergence from the results of Bender and Teuber (1946) is apparent in the finding that completion is not limited to brief exposure just above threshold but still occurs in many cases with exposures lasting up to one and a half seconds.

As a first step towards explaining completion it is necessary to define the conditions under which it occurs. The most striking correlations were with lesions of the parietal lobe and with the symptom of unawareness of field defect. There was a trend towards a relation to unilateral neglect of space.

Is the relationship of completion to a lesion of a parietal lobe a necessary or coincidental one? A number of reasons why it might be coincidental must be evaluated. Did the patients with parietal lobe disease have larger lesions and is completion connected with the degree of mental deterioration? The results have shown that there is no significant correlation between completion and mental deterioration, in contrast to the view put forward by Pollack et al. (1957), and in so far as this is a guide to the extent of the lesion, no other guide being available, this too is unrelated to the phenomenon. Did the patients with parietal lobe disease have hemianopias either of more or less long standing than the others and is completion related in some way to a difference in duration of field defect? The exact duration of hemianopia cannot usually be 0 assessed, particularly in those patients who are unaware of it, but in so far as duration of field defect is related to total duration of illness from the time of the appearance of the first symptom, there is no significant difference between the two groups of patients in this respect. Is completion related to either the acute or insidious onset of the field defect This also cannot be directly assessed but, bearing in mind that in patients with cerebrovascular disease the onset of hemianopia is usually acute whereas in those with cerebral tumour it develops gradually, no significant correlation appears.

It is difficult to escape the conclusion that the relationship between the occurrence of completion and parietal lobe disease is a specific one.

Unawareness of field defect, and, to a lesser extent, unilateral neglect of space have both been shown to be positively correlated with completion. Both symptoms have been thought to occur most commonly with parietal lobe lesions (Critchley, 1953) though some have claimed them as the consequence of widespread rather than localized disease. Thus Weinstein and Kahn (1950) regard general mental deterioration as essential for the appearance of unawareness or denial of defect. Even if this were the case, however, a parietal lesion may still be a necessary condition of its appearance. Similar arguments apply to the contention of Pollack et al. (1957) that unilateral neglect of space occurs only in the presence of mental deterioration. In the present series 11 of 12 patients with parietal lesions were unaware of their field defects whereas all with 
lesions sparing the parietal lobe were aware of their field defects. The latter included five patients with pure occipital lesions. Thus while in this series parietal lobe disease was essential for the unawareness of hemianopia, mental deterioration was not.

A similar situation may hold for unilateral neglect of extrapersonal space. This was found in seven of the patients with parietal lobe disease and in only one of those without it. In this series unilateral neglect of space was related to parietal lobe disease but no relation was found between unilateral neglect and mental deterioration, and the latter has been shown not to be essential for the development of unilateral neglect. There was no significant difference in the laterality of lesions associated with the tendency to 'complete', but there was a trend favouring right-sided (minor hemisphere) lesions.

The patient who completes has reported seeing a full figure when objectively only a half figure was visible. Does the misinterpretation arise at a conscious or unconscious level? If conscious, he would then be deliberately reporting a whole though aware of having only perceived a part. There was nothing about the patients' behaviour to suggest malingering of this kind, and when partial figures were exposed fully within the seeing field they were correctly reported.

If the error is at an unconscious level may it be a confabulatory response asserting the integrity of the visual field to substantiate the verbal denial of field defect? Perhaps, but it must be pointed out that unawareness of field defect does not necessarily imply its denial (Sandifer, 1946). To establish confabulation as the cause of completion, active denial, not merely unawareness, must be demonstrated. In this series no attempt was made to ascertain (as could be done by questioning and by demonstration of the field defects) whether the patients who were unaware of their field defects would go so far as to deny them.

The alternative is that these patients tend to take for granted information that should have come from the affected side of the visual field. Where they have no definite information about the presence or absence of the rest of the figure, information coming from the side subserved by the damaged hemispheres loses importance, or is neglected in comparison with information entering on the intact side. In other words, the absence of the part of the figure on the affected side is neglected. This would relate the phenomenon of completion to other unilateral neglect phenomena and to visual inattention in which, when two stimuli are simultaneously presented in the two half fields of vision, only that on the unaffected side is remarked upon.

Whichever proves to be the correct explanation, the completion phenomenon takes its place as a localizing sign of parietal lobe disease.

\section{SUMMARY}

Single geometrical forms were presented by means of a tachistoscope to a series of patients with homonymous hemianopia in such a way that only half of each form fell within the intact half field of vision. The results showed that some patients reported seeing only those sections of the forms that were objectively visible, and in this way resembled normal control subjects, but others reported seeing complete forms although it was not possible for them actually to have done so. This tendency to 'complete' forms across homonymous hemianopic field defects was found to be strongly associated with the presence of a parietal lobe lesion of either hemisphere, as well as with the symptom of unawareness of field defect. Some possible explanations of the phenomenon of 'completion' are discussed, and attention is drawn to its localizing value for parietal lobe disease.

\section{A P P E N D I X \\ CASE SUMMARIES}

CASE 1 Mr. T. H. (No. 82561), aged 61, was admitted complaining of numbness in the legs and difficulty in walking for 18 months. Examination showed intellectual deterioration, a left homonymous hemianopia, spastic left arm and leg, sensation impaired in the left arm and leg, neglect of the left half of the visual field, and retinal arteriosclerosis. Blood pressure was $130 / 80 \mathrm{~mm}$. Hg. A lumbar air encephalogram revealed generalized cerebral atrophy more marked on the right side. A right carotid arteriogram showed narrowing of the internal carotid artery in the region of the siphon. Psychological testing revealed a moderate degree of dementia and a marked right parietal syndrome. Completion was $97 \%$.

CASE 2 Mr. G. E. (No. 81965), aged 23, was admitted for investigation of focal epilepsy. Examination showed left homonymous hemianopia and left hemiparesis, and neglect of the left half of the visual field. A lumbar air encephalogram revealed a large right parietal mass. At craniotomy a right parietal tumour was partly removed. Histology revealed a malignant ependymoma. Completion was $93 \%$.

CASE 3 Mrs. V. F. (No. 80271), aged 60, was admitted complaining of headaches and visual hallucinations for one year. Examination showed left homonymous hemianopia; the central nervous system was otherwise normal. A ventriculogram demonstrated a right parietooccipital mass. At craniotomy a large meningioma was removed from the parieto-occipital area. Completion was $100 \%$. 
CASE 4 Mrs. M. A. (No. 2789), aged 63, was admitted with suspected recurrence of a right occipital meningioma removed in 1943. Examination showed left homonymous hemianopia, sensation to pin-prick diminished over the left side of the face, sensory impairment of the left arm and leg, and left spastic weakness. At craniotomy a right parieto-occipital meningioma was partially removed. Completion was $87 \%$.

CASE 5 Mr. R. C. (No. 80312), aged 47, was admitted with left hemiplegia of a few hours' duration. Examination showed that he was semi-comatose, with marked neck stiffness and a left hemiplegia. Blood pressure was 200/100 mm. Hg. The cerebrospinal fluid was bloodstained and xanthochromic. The patient was treated conservatively and gradually improved. At the time of psychological investigations he was cooperative but mentally slow. There was a left homonymous hemianopia, left hemiparesis with sensory impairment, and marked visuo-spatial agnosia. Completion was $91 \%$.

CASE 6 Mrs. H. B. (No. 81501), aged 61, was admitted with progressive weakness and clumsiness for six months. Examination showed some mental deterioration, left homonymous hemianopia, left hemiparesis, and joint position sense impaired on the left. A right carotid arteriogram showed pathological vessels indicating a right posterior parietal tumour, and a biopsy revealed a cystic astrocytoma, grade III. Completion was $100 \%$.

CASE 7 Mr. E. M. (No. 80225), aged 44, was admitted complaining of left-sided headaches for 18 months, and deterioration of vision and difficulty in reading and writing. Examination showed bilateral papilloedema, right homonymous hemianopia, and mild right hemiparesis. There was a marked dysphasia, a complete alexia, and mental deterioration. At craniotomy a large left parieto-occiputal parasagittal meningioma was completely removed. Completion was $100 \%$.

CASE 8 Mr. G. M. (No. 42986), aged 34, was admitted for investigation of long-standing epilepsy and recent onset of left hemiparesis and dysphasia. Examination showed left homonymous hemianopia, left hemiparesis, left-sided sensory impairment, receptive and expressive dysphasia, and mental deterioration. Psychological testing revealed a visuo-spatial agnosia. A lumbar air encephalogram showed moderate dilatation of the lateral ventricles; all other investigations were negative. Clinical opinion was that there was a predominantly right parietal lesion in spite of dysphasia in this right-handed man. Completion was $93 \%$.

CASE 9 Miss M. A. (No. 80081), aged 55, was admitted for investigation of epilepsy of late onset. Examination showed left homonymous hemianopia, mild pyramidal and sensory signs on the left. Angiography showed a right posterior temporo-parietal space-occupying lesion. Biopsy revealed an astrocytoma, grade II, in the parietal region. Completion was $80 \%$.

CASE 10 Mr. J. L. (No. 94594), aged 65, was admitted complaining of unsteadiness of gait and reading difficulty since the sudden onset of right hemiparesis and rightsided sensory abnormalities a year earlier. Examination showed right homonymous hemianopia and mild right hemiparesis. Blood pressure was $180 / 100 \mathrm{~mm}$. $\mathrm{Hg}$. He had spelling dyslexia and difficulty in picture interpretation. Clinical opinion was of a vascular lesion of the left hemisphere, affecting mainly the left parietal lobe. Completion was $85 \%$.

CASE 11 Mr. T. H. (No. 93649), aged 63, was admitted complaining of the sudden onset of reading difficulty eight months earlier and clumsiness of the hands, especially of the right, which had been getting worse. Examination showed right homonymous hemianopia, mild right hemiparesis, and sensory impairment in the right arm and leg, moderate dysphasia, and complete alexia. Blood pressure was $220 / 110 \mathrm{~mm}$. Hg. A lumbar air encephalogram showed generalized cortical atrophy. Clinical opinion was of cerebrovascular disease particularly affecting the left parietal region. Completion was $100 \%$.

CASE 12 Mrs. E. B. (No. 68977), aged 36, was admitted two years previously for investigation of blackouts and headaches. Examination showed a partial right homonymous field defect. A vertebral arteriogram showed a large angioma in the left occipital pole, fed by the posterior cerebral artery. A left carotid arteriogram was normal. At craniotomy the angioma was removed together with the left occipital pole. Post-operativelyo there was right homonymous hemianopia; the centralo nervous sytem was otherwise normal. No change in signs at the time of psychological testing two years after operation. Completion was $0 \%$.

CASE 13 Mr. A. R. (No. 80799), aged 70, was admitted for investigation of flashing lights in the right visual field and failing vision on the right side. Examination showed right homonymous hemianopia and retinal arteriosclerosis. Blood pressure was $140 / 95 \mathrm{~mm}$. $\mathrm{Hg}$. The central nervous system was otherwise normal. Clinical opinion was of occlusion of the left posterior cerebral artery. Completion was $37 \%$.

CASE 14 Mr. E. M. (No. 78016), aged 63, was admitted complaining of inability to see objects in his right visual field for two months and of double vision for two days. Examination showed right homonymous hemianopia, limitation of conjugate gaze to the right, and vertical nystagmus. There was no weakness of the limbs but deep reflexes were exaggerated on both sides; the central nervous system was otherwise normal. Blood pressure was $140 / 95 \mathrm{~mm}$. Hg. Clinical opinion was of basilar artery disease with posterior cerebral artery occlusion. Completion was $0 \%$.

CASE 15 Mr. H. W. (No. 15424), aged 40, was admitted with a 15-year history of temporal lobe epilepsy. Examination showed left homonymous hemianopia (most marked in the upper quadrant), bilateral papilloedema, and slight weakness and minimal sensory changes in the left arm 
and leg; also mental deterioration. A right carotid arteriogram showed a mass within the right temporal lobe. At craniotomy a large cystic glioma was removed with amputation of the temporal lobe. Completion was $37 \%$.

CASE 16 Mr. E. M. (No. 80852), aged 54, was admitted for investigation of poor vision for eight months. Examination showed right homonymous hemianopia but the central nervous system was otherwise normal. Blood pressure was $120 / 80 \mathrm{~mm}$. Hg. A lumbar air encephalogram was normal. Clinical opinion was of thrombosis of the left posterior cerebral artery. Completion was $17 \%$.

CASE 17 Mr. C. S. (No. 82028), aged 55, was admitted complaining of recurrent headaches for one year and blurring of vision for seven months. Examination showed incomplete left homonymous hemianopia affecting mainly the upper quadrant, mild left hemiparesis, and mental deterioration. Blood pressure was $190 / 90 \mathrm{~mm}$. $\mathrm{Hg}$. A right carotid arteriogram was normal. A lumbar air encephalogram showed mild dilatation of the lateral ventricles. Clinical opinion was of a vascular lesion of the right hemisphere mainly affecting the right temporal region. Completion was $12 \%$.

CASE 18 Mr. S. P. (No. 72414), aged 65, was admitted for investigation of headaches of a few months' duration and poor vision in the left visual field. Examination showed left homonymous hemianopia; the central nervous system was otherwise normal. Blood pressure was $190 / 90 \mathrm{~mm}$. $\mathrm{Hg}$. A right carotid arteriogram was normal but a vertebral arteriogram showed complete occlusion of the right posterior cerebral artery. Completion was $8 \%$.

CASE 19 Mr. K. S. (No. 79125), aged 25, was admitted for investigation of poor vision. Examination showed loss of vision in the temporal field of the left eye and total loss of vision in the right eye; optic discs were pale; he was mentally deteriorated. At craniotomy the right optic nerve was depressed downwards by tumour, probably arising on the under surface of the right frontal lobe. Biopsy was negative. Clinical opinion was of a right frontal glioma. Completion was $30 \%$.
CASE 20 Mr. W. S. (No. 95897), aged 57, was admitted for investigation of sudden onset of weakness of the right arm a few weeks before admission having had the sudden onset of visual failure in the right half field, and subsequently developed transient left hemiparesis. Examination showed dysphasia, right homonymous hemianopia, and right hemiplegia with sensory loss in the right arm and leg. Blood pressure was $190 / 110 \mathrm{~mm}$. $\mathrm{Hg}$. Gradual improvement of speech and power but right homonymous hemianopia persisted. Clinical opinion was of cerebrovascular disease. Completion was $0 \%$.

I should like to thank Dr. Eliot Slater and the Institute of Neurology, National Hospital, Queen Square, for facilities to conduct this study; the physicians and surgeons of the National Hospital, for permission to study cases under their care; Professor O. L. Zangwill for advice and encouragement; Dr. R. W. Gilliat for help with the clinical summaries and the presentation of this work; and Mr. A. H. Prickett, Department of Photography, National Hospital, for preparing and photographing the figures. Part of this work was carried out with the support of a Medical Research Council grant.

\section{REFERENCES}

Bender, M. B., and Teuber, H. L. (1946). Arch. Neurol. Psychiat. (Chicago), 55, 627.

Critchley, M. (1950). Trans. Ophthal. Soc. U.K., 1949, 69, 95.

- (1953). The Parietal Lobes. Arnold, London.

Diefendorf, A. R., and Dodge, R. (1908). Brain, 31, 451.

Dodge, R. (1907). Psychol. Rev. Monogr. Suppl. 8, No. 4.

Fuchs, W. (1920). Z. Psvchol., 84, 67.

Helmholtz, H. von (1924-5). Helmholtz's Treatise on Physiological Optics, ed. J. P. C. Southall. Optical Society of America.

Kinsbourne, M., and Warrington, E. K. (1962). Quart J. exp. Psychol. (in press).

Koffka, K. (1935). Principles of Gestalt Psychology. Harcourt, Brace, New York; Kegan Paul, London.

Pollack, M., Battersby, W. S., and Bender, M. B. (1957). J. comp. physiol. Psychol., 50, 220.

Poppelreuter, W. (1917). Die psychischen Schädigungen durch Kopfschuss im Kriege 1914-16; die Störungen der niederen und höheren Sehleistungen durch Verletzungen des Okzipitalhirns. Voss, Leipzig

Sandifer, P. H. (1946). Brain, 69, 122.

Warrington, E. K. (1960). Completion of Visual Forms Across Hemianopic Field Defects. Ph.D. Thesis. London University.

Weinstein, E. A., and Kahn, R. L. (1950). Arch. Neurol. Psychiat. (Chicago), 64, 772. 